\title{
Drug use disorder and risk of incident and fatal breast cancer: a nationwide epidemiological study
}

\author{
Disa Dahlman ${ }^{1}$ (1) $\cdot$ Hedvig Magnusson ${ }^{1} \cdot{\text { Xinjun } \mathrm{Li}^{1} \cdot \operatorname{Jan} \text { Sundquist }}^{1,2,3} \cdot$ Kristina Sundquist $^{1,2,3}$
}

Received: 10 August 2020 / Accepted: 26 October 2020 / Published online: 6 November 2020

(c) The Author(s) 2020

\begin{abstract}
Purpose Breast cancer is one of the most common cancer forms in women and it is often detected by screening. However, women with drug use disorders (DUD) are less likely to be reached by screening programs. In this study, we aimed to investigate breast cancer incidence, mortality and stage at time of diagnosis among women with DUD compared to the general female population in Sweden.

Methods We performed a follow-up study based on Swedish national register data for the period January 1997-December 2015. The study was based on 3,838,248 women aged 15-75 years, of whom 50,858 were registered with DUD. Adjusted hazard ratios (HRs) for incident and fatal breast cancer, and cancer stage at time of diagnosis, were calculated for women with and without DUD using Cox regression analysis.

Results DUD was associated with incident breast cancer (HR 1.08, 95\% confidence interval [CI] 1.02-1.14, $p=0.0069$ ), fatal breast cancer (HR 1.60, 95\% CI 1.42-1.82, $p<0.001$ ), and stage IV breast cancer, i.e. metastasis at diagnosis (HR 2.06, 95\% CI 1.44-2.95, $p<0.001)$.

Conclusions Women with DUD were identified as a risk group for incident, fatal and metastasized breast cancer, which calls for attention from clinicians and policy makers. Cancer screening attendance and other healthcare seeking barriers are likely to affect the risk increase among women who use drugs; however, more research is needed on the underlying mechanisms.
\end{abstract}

Keywords Breast cancer $\cdot$ Drug abuse $\cdot$ Mortality $\cdot$ Sweden

\begin{abstract}
Abbreviations
BMI Body mass index

DUD Drug use disorders

NPR National patient register

OST Opioid substitution treatment

SES Socioeconomic status
\end{abstract}

Electronic supplementary material The online version of this article (https://doi.org/10.1007/s10549-020-05998-4) contains supplementary material, which is available to authorized users.

Disa Dahlman

disa.dahlman@med.lu.se

1 Center for Primary Health Care Research, Department of Clinical Sciences, Lund University/Region Skåne, Box 503 22, Malmö, Sweden

2 Department of Family Medicine and Community Health, Icahn School of Medicine At Mount Sinai, New York, USA

3 Center for Community-Based Healthcare Research and Education (CoHRE), School of Medicine, Shimane University, Matsue, Japan

\section{Introduction}

Drug use disorders (DUD) are associated with a range of adverse health outcomes including increased mortality rates $[1,2]$. For example, patients in opioid substitution treatment (OST) are shown to have significantly higher non-drugrelated mortality, including in cancer, than the general population $[3,4]$. The mortality rates are especially increased in patients older than 55 years [3], which is worrying since the OST populations are aging [5]. Psychiatric comorbidity is also common among people who use drugs and people in OST [6-8].

The adverse health outcomes associated with DUD could partly be related to unmet health care needs [9-11] including non-participation in cancer screening programs, such as for breast cancer [12, 13], cervical cancer [13-15] and colorectal cancer [13]. It is therefore likely that women with DUD have higher mortality in common cancers, e.g. breast cancer, and a delayed diagnosis.

In addition, women with DUD often have poor socioeconomic status (SES), which may further deteriorate their 
chances of achieving good health. While high SES is associated with increased incidence of breast cancer, breast cancer survival is lower among women with low SES [16], which in turn is related to lifestyle factors. For example, excessive alcohol consumption is associated with breast cancer [17, 18], and is also overrepresented among people with DUD $[11,19,20]$. Tobacco smoking is also associated with low SES [21] and has been identified as a risk factor for breast cancer [22]. In addition, tobacco smoking is highly prevalent among people with DUD [19, 23, 24].

Breast cancer is the most commonly diagnosed cancer and the leading cause of cancer death among women globally, with over two million women being diagnosed each year [25]. In Sweden, breast cancer is one of the leading causes of death among middle aged women [26]. Breast cancer screening through mammography every $18-24$ months is therefore offered to Swedish women at no or a low cost between 40 and 74 years of age [26], since 1997. The screening program reduces the breast cancer mortality with 16-25\% [26]. All healthcare in Sweden is tax financed and strongly subsidized for the individual [27].

Despite the critical need of more knowledge on whether women with DUD have a higher breast cancer incidence or a poorer prognosis when diagnosed with breast cancer, we have only found one previous study on DUD and breast cancer [4]. In this study, opioid dependence was associated with lower breast cancer mortality compared to the general female population in Australia [4]. We therefore aimed to examine breast cancer incidence, mortality, and stage at the time of diagnosis among women with DUD compared to the general female population in Sweden, after taking potential confounders, including SES, into account.

\section{Methods}

\section{Data sources}

We performed a retrospective cohort study of national register data. A dataset was constructed through linkage of data from the following Swedish national registers: the Swedish National Patient Register (NPR) for inpatient care (1964-2015) and outpatient care (2001-2015), the Total Population Register, the Swedish Cause of Death Register (1961-2015), the Swedish Prescribed Drug Register (2005-2015), the Swedish Cancer Register (1958-2015), the Crime Register (1973-2015), and the Suspicion Register (1998-2015). All linkages were performed using the national 10-digit civic registration number, which is assigned to each person in Sweden upon birth or immigration to the country. This number was replaced by a serial number to ensure the integrity of all individuals. The registers contain, e.g., individual-level data on age, sex, education, hospital admissions, dispensed drugs and breast cancer diagnoses on a nationwide basis, including the study population of women aged 15-75 years in Sweden.

Ethical approval for the study was obtained from the Regional Ethical Review Board in Lund (file number 2012/795).

\section{Participants}

Women 15-75 years of age at January 1, 1997 were included in the study. We excluded individuals with a diagnosis of breast cancer between January 1, 1991 and December 31,1996 , i.e., those with an earlier diagnosed cancer $(n=37,533)$. Finally, a total of 3,838,248 individuals were included in the study (Supplementary Fig. 1). The comparison group were women without an incident of DUD.

\section{Exposure}

Drug use disorders (DUD) were identified in the following registries any time during the study period: the NPR by relevant ICD-10 codes (F10-F19: mental and behavioral disorders due to psychoactive substance use, except those due to alcohol or tobacco); the Suspicion Register, which records suspected crimes related to drug use by codes 3070 (driving under the influence of drugs), 5010 (drug possession), 5011 (drug use), and 5012 (drug possession and use); and the Crime Register, which records convictions by references to laws covering narcotics (law 1968:64, paragraph 1, point 6) and drug-related driving offenses (law 1951:649, paragraph 4, subsection 2 and paragraph $4 \mathrm{~A}$, subsection 2). DUD was also identified in individuals (excluding any other cancer patients) in the Prescribed Drug Register who had filled prescriptions for hypnotics and sedatives (Anatomical Therapeutic Chemical [ATC] Classification System N05C and N05BA) or opioids (ATC: N02A) in average dosages of more than four defined daily doses a day for 12 months.

\section{Outcome variables}

\section{Incident breast cancer}

The outcome variable was a diagnosis of breast cancer in the Swedish Cancer Register during the study period (1997-2015). The 7th revisions of the International Classification of Diseases (ICD-7) was used to identify breast cancer (ICD-7 170). 


\section{Fatal breast cancer}

The outcome variable was a diagnosis of breast cancer in the Swedish Cause of Death Register during the study period, using the 10th revision of the ICD to identify breast cancer (ICD-10 C50).

\section{Breast cancer stage at time of diagnosis}

Stage 0-IV, obtained from the Swedish Cancer Register, based on the TNM classification. TNM is short for Tumor (tumor characteristics, including size), Nodes (spread to nearby lymph nodes), and Metastases (spread to other parts of the body).

\section{Covariates}

Age was recorded at January 1, 1997 into three groups: 15-34 years, 35-49 years and 50-75 years.

Educational attainment as of January 1, 1997 was categorized as $\leq 9$ years (partial or complete compulsory schooling), 10-12 years (partial or complete secondary schooling) and $>12$ years (some or completed college and/or university studies). Prior to the statistical analysis, educational attainment was dichotomized into "up to 12 years" and "> 12 years".

Marital status as of January 1, 1997 was classified as married/cohabiting, unmarried, divorced or widowed. We used two categories in the analysis, i.e., married/cohabiting vs. not married/cohabiting (including all unmarried, divorced and widowed women).

Region of residence was recoded into "large city" and "small city/countryside" from the original categories "large city", "southern Sweden" and "northern Sweden". Large cities were defined as one of the three largest cities in Sweden (Stockholm, Gothenburg and Malmö). "Southern Sweden" and "northern Sweden" were recoded into "small city/ countryside".

Social welfare was defined as Yes (received) and No (not received).

Alcohol use disorder was identified according to ICD-10 F10 and K70 during the study period.

\section{Statistical analysis}

Cox regression models were used to estimate Hazard ratios (HRs) with a 95\% confidence interval (CI) to test for the association between DUD and incident breast cancer, fatal breast cancer, and cancer stage at diagnosis in the women. The women were followed for time to the first breast cancer outcome, death, migration from Sweden, or until December 31, 2015. The follow-up started on January 1, 1997 and ended on December 31, 2015. The average follow-up time was $16.6 \pm 3.6$ years. We used two models: Model 1 was adjusted for age at entering the cohort; Model 2 was adjusted for age and the covariates listed above. The proportionality assumptions were checked by plotting the incidence rates over time and by calculating Schoenfeld (partial) residuals and these assumptions were fulfilled (Supplementary Fig. 2).

All statistical analyses were performed using SAS version 9.4 (SAS Institute Inc. Cary, NC, USA). A two-tailed $p$-value of $<0.05$ was used for statistical significance for the outcomes.

A sensitivity analysis was conducted using data obtained from the Swedish Medical Birth Register. Information on the smoking history, parity, age at first delivery and body mass index (BMI) of the women (mothers) from the Medical Birth Register was identified and included in the analysis. The initial population for the women was $1,349,971$ because data on smoking were only collected in the latter age cohorts of pregnant women. Another sensitivity analysis was conducted using data obtained from the Swedish Multi-generation Register. Information on the family history (mothers or sisters) of breast cancer was identified. The initial population for the women was $2,458,279$ because data on the second-generation daughters were collected only among those born in 1932 and onwards due to the nature of the register. An additional analysis was performed with the exposure variable DUD replaced with opioid use disorder, defined as ICD-10 codes F11, and retrieved from the NPR.

\section{Results}

\section{Baseline characteristics}

The study population included 3,838,248 women aged 15-75 years in January 1, 1997. The mean age was 42.5 years (standard deviation 16.9), $38.7 \%$ were married/ cohabiting, $41.6 \%$ were living in small cities/countryside, $44.1 \%$ had more than 12 years of education, and $7 \%$ had received social welfare (Table 1). DUD was incident in $1.3 \%$ of the study population $(n=50,858)$. Women with DUD were younger than the comparison group, had shorter education, had more often received social welfare, were more often living in large cities, and were more often not married/ cohabiting.

\section{Incident breast cancer and DUD}

In the study population, $2.8 \%(n=108,986)$ received a breast cancer diagnosis. Cox regression analysis adjusted only for age (Model 1) showed a statistically significant positive association between DUD and breast cancer (HR 1.14, 95\% CI 1.08-1.20; Table 2). The association remained in Model 2 after adjustment also for educational attainment, social 
Table 1 Population and number of events of incident and fatal breast cancer

\begin{tabular}{|c|c|c|c|c|c|c|}
\hline & \multicolumn{2}{|c|}{ Total population } & \multicolumn{2}{|c|}{ Incident breast cancer } & \multicolumn{2}{|c|}{ Fatal breast cancer } \\
\hline & No & $\%$ & No & $\%$ & No & $\%$ \\
\hline \multicolumn{7}{|l|}{ Drug use disorders } \\
\hline Non & $3,787,390$ & 98.7 & 107,676 & 98.8 & 16,692 & 98.4 \\
\hline Yes & 50,858 & 1.3 & 1310 & 1.2 & 267 & 1.6 \\
\hline \multicolumn{7}{|l|}{ Age groups (years) } \\
\hline $15-34$ & $1,443,369$ & 37.6 & 11,132 & 10.2 & 1061 & 6.3 \\
\hline $35-49$ & $1,013,516$ & 26.4 & 32,798 & 30.1 & 3868 & 22.8 \\
\hline $50-75$ & $1,381,363$ & 36.0 & 65,056 & 59.7 & 12,030 & 70.9 \\
\hline \multicolumn{7}{|l|}{ Educational attainment } \\
\hline$<12$ years & $1,732,700$ & 45.1 & 64,636 & 59.3 & 11,324 & 66.8 \\
\hline $12+$ years & $1,694,316$ & 44.1 & 43,300 & 39.7 & 5307 & 31.3 \\
\hline Unknown & 411,232 & 10.7 & 1050 & 1.0 & 328 & 1.9 \\
\hline \multicolumn{7}{|l|}{ Social welfare } \\
\hline Non & $3,569,683$ & 93.0 & 103,761 & 95.2 & 16,124 & 95.1 \\
\hline Yes & 268,565 & 7.0 & 5225 & 4.8 & 835 & 4.9 \\
\hline \multicolumn{7}{|l|}{ Region of residence } \\
\hline Large city & $1,594,505$ & 41.5 & 54,934 & 50.4 & 8432 & 49.7 \\
\hline Small city/countryside & $1,597,877$ & 41.6 & 51,638 & 47.4 & 7839 & 46.2 \\
\hline Unknown & 645,866 & 16.8 & 2414 & 2.2 & 688 & 4.1 \\
\hline \multicolumn{7}{|l|}{ Marital status } \\
\hline Married/cohabiting & $1,484,886$ & 38.7 & 62,933 & 57.7 & 9097 & 53.6 \\
\hline Not married/cohabiting & $1,707,496$ & 44.5 & 43,639 & 40.0 & 7174 & 42.3 \\
\hline Unknown & 645,866 & 16.8 & 2414 & 2.2 & 688 & 4.1 \\
\hline \multicolumn{7}{|l|}{ Alcohol use disorder } \\
\hline Non & $3,775,382$ & 98.4 & 107,101 & 98.3 & 16,777 & 98.9 \\
\hline Yes & 62,866 & 1.6 & 1885 & 1.7 & 182 & 1.1 \\
\hline All & $3,838,248$ & 100.0 & 108,986 & 100.0 & 16,959 & 100.0 \\
\hline
\end{tabular}

Table 2 Association of drug use disorders (DUD) and incident breast cancer

\begin{tabular}{|c|c|c|c|c|c|c|c|c|c|}
\hline \multirow{3}{*}{$\begin{array}{l}\text { Covariates } \\
\text { DUD (vs. non) }\end{array}$} & \multirow{3}{*}{$\begin{array}{c}\text { Person years follow-up } \\
852,294\end{array}$} & \multicolumn{4}{|c|}{ Model 1} & \multicolumn{4}{|c|}{ Model 2} \\
\hline & & \multirow{2}{*}{$\frac{\mathrm{HR}}{1.14}$} & \multicolumn{2}{|c|}{$95 \% \mathrm{CI}$} & \multirow{2}{*}{$\frac{p \text {-value }}{<0.001}$} & \multirow{2}{*}{$\frac{\mathrm{HR}}{1.08}$} & \multicolumn{2}{|c|}{$95 \% \mathrm{CI}$} & \multirow{2}{*}{$\frac{p \text {-value }}{0.0069}$} \\
\hline & & & 1.08 & 1.20 & & & 1.02 & 1.14 & \\
\hline \multicolumn{10}{|l|}{ Age (vs. age $15-34$ years) } \\
\hline $35-49$ & $17,472,852$ & 4.20 & 4.12 & 4.30 & $<.0001$ & 14.58 & 4.48 & 4.68 & $<.0001$ \\
\hline $50-75$ & $21,504,144$ & 6.86 & 6.72 & 7.00 & $<.0001$ & 17.96 & 7.79 & 8.13 & $<.0001$ \\
\hline Educational attainment $<12$ years (vs. $12+$ years) & $34,957,420$ & & & & & 0.77 & 0.76 & 0.78 & $<.0001$ \\
\hline Social welfare (vs. no social welfare) & $4,504,849$ & & & & & 0.89 & 0.87 & 0.92 & $<.0001$ \\
\hline Region of residence large city (vs. small city/countryside) & $26,375,130$ & & & & & 1.36 & 1.34 & 1.37 & $<.0001$ \\
\hline Marital status not married/cohabiting (vs. married/cohabiting) & $28,414,388$ & & & & & 1.14 & 1.12 & 1.15 & $<.0001$ \\
\hline Alcohol use disorder (vs. non) & $1,025,119$ & & & & & 1.11 & 1.06 & 1.17 & $<.0001$ \\
\hline
\end{tabular}

$N=3,838,248$. Total person years follow-up $63,903,192$

$H R$ hazard ratio, $C I$ confidence interval

Model 1: Adjusted for age; Model 2: Adjusted for age, educational attainment, social welfare, region of residence, marital status and alcohol use disorder

welfare, region of residence, marital status and alcohol use disorder (HR 1.08, 95\% CI 1.02-1.14). Inverse associations were found between breast cancer and education $<12$ years
(HR $0.77,95 \%$ CI $0.76-0.78$ ) as well as between breast cancer and social welfare (HR 0.89 , 95\% CI 0.87-0.92). Living in a large city (HR 1.36, 95\% CI 1.34-1.37), being not 
married/cohabiting (HR 1.14, 95\% CI 1.12-1.15), of age 35-49 (HR 4.58, 95\% CI 4.48-4.68) and 50-75 years (HR 7.96, 95\% CI 7.79-8.13), and alcohol use disorder (HR 1.11, 95\% 1.06-1.17) were all positively associated with incident breast cancer in Model 2.

\section{Fatal breast cancer and DUD}

In the study population, $0.4 \%(n=16,959)$ died of breast cancer during the study period. We found a significant association between DUD and fatal breast cancer after adjustment for age in Model 1 (HR 1.63, 95\% CI 1.44-1.84) and remained significant after adjustment also for age, educational attainment, social welfare, region of residence, marital status and alcohol use disorder in Model 2 (HR 1.60, 95\% CI 1.42-1.82). In Model 2, fatal breast cancer was associated with living in a large city (HR 1.33, 95\% CI 1.29-1.37), being not married/cohabiting (HR 1.35, 95\% CI 1.31-1.39), of age 35-49 (HR 5.58, 95\% CI 5.21-5.98) and 50-75 years (HR 14.44, 95\% CI 13.53-15.42), and alcohol use disorder (HR $0.64,95 \% 0.55-0.74$ ). No statistically significant associations between fatal breast cancer and educational attainment or social welfare were found (Table 3).

\section{Breast cancer stage and DUD}

After exclusion of women without data on TNM-stage, 55,234 (50.7\% of the 108,986 women with breast cancer) remained for the analysis. Of these, 673 had DUD. In the sub-sample of women with breast cancer, DUD was associated with stage II (HR 1.13, 95\% CI 1.01-1.27) and stage IV (HR 2.06, 95\% CI 1.44-2.95) after adjustment for age,
Table 4 Association of drug use disorders and breast cancer stage at time of diagnosis among women with malignant breast cancer

\begin{tabular}{lccccc}
\hline Cancer stage & No. of cases & HR* & \multicolumn{2}{l}{$95 \%$ CI } & $p$-value \\
\hline Stage 0 & 429 & 1.45 & 0.63 & 3.33 & 0.3811 \\
Stage I & 28,176 & 0.91 & 0.81 & 1.02 & 0.1130 \\
Stage II & 23,145 & 1.13 & 1.01 & 1.27 & 0.0402 \\
Stage III & 2016 & 1.26 & 0.88 & 1.81 & 0.2008 \\
Stage IV & 1468 & 2.06 & 1.44 & 2.95 & $<0.001$ \\
\hline
\end{tabular}

$N=3,873,741$. Cases of breast cancer $=55,234$. Total person years follow-up 63,536,723

$H R$ hazard ratio, $C I$ confidence interval

*Full adjusted (for age, educational attainment, social welfare, region of residence, marital status and alcohol use disorder)

social welfare, educational attainment, region of residence, marital status and alcohol use disorder (Table 4).

\section{Additional analyses}

We conducted an additional analysis of incident and fatal breast cancer on a sub-sample of women with available information on tobacco smoking history, parity, age at first delivery, and BMI. DUD was significantly associated with fatal breast cancer (HR 1.63; 95\% CI 1.21-2.19; $p=0.0013$ ), when adjusting for age, educational attainment, social welfare, region of residence, marital status, alcohol use disorder, tobacco smoking, parity, age at first delivery, and BMI (Supplementary Table 2).

An additional analysis of incident and fatal breast cancer on a sub-sample of women with available information on

Table 3 Association of drug use disorders (DUD) and fatal breast cancer

\begin{tabular}{|c|c|c|c|c|c|c|c|c|c|}
\hline \multirow{3}{*}{$\begin{array}{l}\text { Covariates } \\
\text { DUD (vs. non) }\end{array}$} & \multirow{3}{*}{$\begin{array}{l}\text { Person years follow-up } \\
862,294\end{array}$} & \multicolumn{4}{|c|}{ Model 1} & \multicolumn{4}{|c|}{ Model 2} \\
\hline & & \multirow{2}{*}{$\begin{array}{l}\mathrm{HR} \\
1.63\end{array}$} & \multicolumn{2}{|c|}{$95 \% \mathrm{CI}$} & \multirow{2}{*}{$\frac{p \text {-value }}{<0.001}$} & \multirow{2}{*}{$\begin{array}{l}\mathrm{HR} \\
1.60\end{array}$} & \multicolumn{2}{|c|}{$95 \% \mathrm{CI}$} & \multirow{2}{*}{$\frac{p \text {-value }}{<0.001}$} \\
\hline & & & 1.44 & 1.84 & & & 1.42 & 1.82 & \\
\hline \multicolumn{10}{|l|}{ Age (vs. age $15-34$ years) } \\
\hline $35-49$ & $17,729,577$ & 5.14 & 4.80 & 5.50 & $<.0001$ & 5.58 & 5.21 & 5.98 & $<.0001$ \\
\hline $50-75$ & $22,030,892$ & 13.17 & 12.37 & 14.02 & $<.0001$ & 14.44 & 13.53 & 15.42 & $<.0001$ \\
\hline Educational attainment $<12$ years (vs. $12+$ years) & $35,461,860$ & & & & & 0.99 & 0.96 & 1.03 & 0.6548 \\
\hline Social welfare (vs. no social welfare) & $4,540,739$ & & & & & 1.01 & 0.94 & 1.08 & 0.8158 \\
\hline $\begin{array}{l}\text { Region of residence large city (vs. small city/country- } \\
\text { side) }\end{array}$ & $26,796,656$ & & & & & 1.33 & 1.29 & 1.37 & $<.0001$ \\
\hline $\begin{array}{l}\text { Marital status not married/cohabiting (vs. married/ } \\
\text { cohabiting) }\end{array}$ & $28,734,712$ & & & & & 1.35 & 1.31 & 1.39 & $<.0001$ \\
\hline Alcohol use disorder (vs. non) & $1,039,030$ & & & & & 0.64 & 0.55 & 0.74 & $<.0001$ \\
\hline
\end{tabular}

$N=3,838,248$. Total person years follow-up $64,740,925$

$H R$ hazard ratio, $C I$ confidence interval

Model 1: Adjusted for age; Model 2: Adjusted for age, educational attainment, social welfare, region of residence, marital status and alcohol use disorder 
family history of breast cancer showed that DUD was significantly associated with fatal breast cancer (HR 1.69; 95\% CI 1.45-1.98; $p<0.001)$, when adjusting for age, educational attainment, social welfare, region of residence, marital status, alcohol use disorder, and family history of breast cancer (Supplementary Table 3).

We found no association between opioid use disorder and incident breast cancer or fatal breast cancer (Supplementary Table 4).

\section{Discussion}

In this population-based study, we identified DUD as a predictor for incident breast cancer, fatal breast cancer, and metastasis at time of breast cancer diagnosis.

To our knowledge, this is the first large-scale study of breast cancer incidence, mortality and stage at diagnosis among women with DUD. Since DUD is frequently associated with alcohol and tobacco dependence [11, 19, 20, 23, 24], we have adjusted for these two risk factors of breast cancer $[17,18,22]$. In additional analyses that adjusted for risk factors for breast cancer $[17,18]$ (smoking, parity, age at first delivery and BMI; and family history of breast cancer), the association between DUD and incident breast cancer became statistically non-significant, suggesting that the risk factors listed above are likely to confound our results for incident but not for fatal breast cancer.

In addition to the above mentioned risk factors, the increased breast cancer mortality and incidence of metastatic breast cancer among women with DUD might be due to barriers towards seeking healthcare and attending breast cancer screening [12]. Previous studies have identified people who use drugs as having a high degree of unmet healthcare needs, barriers towards seeking healthcare and experience of stigma during healthcare encounters [9-11, 28]. Drug use is further often associated with poor SES, psychosocial vulnerability $[8,29]$ and psychiatric comorbidity $[6,7]$; these factors are also associated with low attendance to screening with mammography [30, 31].

Our data on breast cancer mortality are incoherent with an Australian study by Randall et al. finding that opioid dependence was associated with lower breast cancer mortality compared to the general population [4]. The authors suggested that their finding may reflect the presence of protective factors for risk of breast cancer among women with DUD, such as giving birth at early age and having had multiple pregnancies. However, their study did not investigate breast cancer incidence. We conducted an additional analysis on opioid use disorder as the independent variable, and found no significant association with incident breast cancer or fatal breast cancer. As opioid dependence is associated with significantly increased mortality due to both drug-related (mainly overdose) and non-drug-related causes of death [1-3], it is possible that fatalities due to other causes than breast cancer might explain the results from Randall et al. [4].

In addition to our main results, we found that low educational attainment and receiving social welfare were inversely associated with breast cancer incidence but not mortality, which is in line with previous research identifying high SES as a risk factor for breast cancer [16]. Carlsen et al. [16] suggest that the positive association with SES may be explained by differences in total parity and age at first fullterm pregnancy. Being not married/cohabiting and living in a large city were predictors of both incident and fatal breast cancer. Alcohol use disorder was associated with incident breast cancer but inversely associated with fatal breast cancer, which might be explained by high fatality rates related to excessive alcohol use, such as liver diseases and other serious diseases.

Our findings have important clinical implications. We have identified women with DUD as a risk group for incident, fatal and metastatic breast cancer, suggesting a need for raised awareness among health care professionals and decision-makers to improve breast cancer survival in women with DUD. Future research regarding cancer screening attendance, and potential barriers to healthcare seeking in general and cancer screening in particular, among women with DUD is needed to decrease these health inequities. We also suggest that assisted smoking cessation should be prioritized in treatment facilities for women with DUD.

\section{Strengths and limitations}

This study analyzed nationwide data from several national registers of high quality. The Swedish Cancer Register has almost $100 \%$ validity and coverage [32-34], the Swedish Total Population Register is nearly $100 \%$ complete $[35,36]$, and the NPR for inpatient care is of documented high quality, with $85-95 \%$ of the diagnoses being valid [37].

Our definition of DUD as a composed variable from five national registers has been used in several previous studies [38, 39]. By using a broad definition ranging from a registration of DUD in the NPR to a registration of drug possession in the Suspicion Register, we aimed to include not only people with clinical DUD noted by the healthcare but also those who were suspected or convicted for a drug-related crime. On the other hand, we might have included women with a more sporadic drug use rather than a DUD. However, the $1.3 \%$ DUD from our register data is similar to the estimated $1.8 \%$ of the Swedish adult population who reported drug use, according to a survey made in 2017 by the Swedish Council for Information on Alcohol and Other Drugs [40].

Data on addiction treatment, types of substances used, or quantification of DUD, would have allowed for more 
refined analyses, but such data are not available on a total population level. Severe DUD, such as injection of heroin, is thought to be more stigmatizing and associated with lower health care seeking and more inadequate preventive health care compared to occasional, recreational drug use. On the other hand, a more severe DUD—especially involving opioids - might be associated with lower cancer mortality due to premature, drug-related death [1,2]. This hypothesis is supported by our additional analysis and constitutes a subject for future research.

\section{Conclusion}

In this study, we found that women who use drugs have higher incidence of breast cancer when compared to the general female population. We also found an association between DUD and fatal breast cancer as well as metastatic breast cancer when receiving the cancer diagnosis. Our findings should raise attention among medical staff and decisionmakers towards a group of women in need of easily accessible breast cancer examinations.

Acknowledgements This work was supported by the National Institute on Drug Abuse at the National Institutes of Health (R01DA030005); and from the Swedish Research Council to Jan Sundquist (2016-01176) and to Kristina Sundquist (2018-02400); and ALF Project Grant, Region Skåne/Lund University, Sweden. The funding agencies had no role in the design and conduct of the study; in the collection, analysis and interpretation of the data; or in the preparation, review or approval of the manuscript. There were no conflicts of interest.

Author contributions DD, HM and KS were responsible for the research idea and study design. XL conducted the data retrieval and statistical analyses. All authors contributed to the interpretation of the results, and manuscript writing. All authors have approved the final manuscript.

Funding Open access funding provided by Lund University. This work was supported by the National Institute on Drug Abuse at the National Institutes of Health (R01DA030005); and from the Swedish Research Council to Jan Sundquist (2016-01176) and to Kristina Sundquist (2018-02400); and ALF project grant, Region Skåne/Lund University, Sweden. The funding agencies had no role in the design and conduct of the study; in the collection, analysis and interpretation of the data; or in the preparation, review or approval of the manuscript. There were no conflicts of interest.

Data availability The data used to support the findings of this study are restricted by the Regional Ethical Review Board in Lund, Sweden, in order to protect patient privacy. Data are available from Kristina Sundquist, kristina.sundquist@med.lu.se for researchers who meet the criteria for access to confidential data.

\section{Compliance with ethical standards}

Conflict of interest Disa Dahlman, Hedvig Magnusson, Xinjun Li, Jan Sundquist and Kristina Sundquist) declares that they have no conflict of interest.

Ethical approval All procedures performed in studies involving human participants were in accordance with the ethical standards of the institutional and/or national research committee and with the 1964 Helsinki declaration and its later amendments or comparable ethical standards. Ethical approval for the study was obtained from the Regional Ethical Review Board in Lund (file number 2012/795).

Consent to participate Only register data were used in the study. Informed consent was not obtained, which was in accordance with ethical approval from the Regional Ethical Review Board in Lund.

Consent for publication Only register data were used in the study. Informed consent was not obtained, which was in accordance with ethical approval from the Regional Ethical Review Board in Lund.

Open Access This article is licensed under a Creative Commons Attribution 4.0 International License, which permits use, sharing, adaptation, distribution and reproduction in any medium or format, as long as you give appropriate credit to the original author(s) and the source, provide a link to the Creative Commons licence, and indicate if changes were made. The images or other third party material in this article are included in the article's Creative Commons licence, unless indicated otherwise in a credit line to the material. If material is not included in the article's Creative Commons licence and your intended use is not permitted by statutory regulation or exceeds the permitted use, you will need to obtain permission directly from the copyright holder. To view a copy of this licence, visit http://creativecommons.org/licenses/by/4.0/.

\section{References}

1. Nyhlén A, Fridell M, Hesse M, Krantz P (2011) Causes of premature mortality in Swedish drug abusers: a prospective longitudinal study 1970-2006. J Forensic Leg Med 18(2):66-72. https://doi. org/10.1016/j.jflm.2011.01.003

2. von Greiff N, Skogens L, Berlin M, Bergmark A (2018) Mortality and cause of death-A 30-year follow-up of substance misusers in Sweden. Subst Use Misuse 53(12):2043-2051. https://doi. org/10.1080/10826084.2018.1452261

3. Gao L, Robertson JR, Bird SM (2019) Non drug-related and opioid-specific causes of 3262 deaths in Scotland's methadone-prescription clients, 2009-2015. Drug Alcohol Depend 197:262-270. https://doi.org/10.1016/j.drugalcdep.2019.01.019

4. Randall D, Degenhardt L, Vajdic CM et al (2011) Increasing cancer mortality among opioid-dependent persons in Australia: a new public health challenge for a disadvantaged population. Aust N Z J Public Health 35(3):220-225. https://doi.org/10.111 1/j.1753-6405.2011.00682.x

5. Han B, Polydorou S, Ferris R, Blaum CS, Ross S, McNeely J (2015) Demographic trends of adults in New York City opioid treatment programs-an aging population. Subst Use Misuse 50(13):1660-1667. https://doi.org/10.3109/10826084.2015.10279 29

6. Savant JD, Barry DT, Cutter CJ et al (2013) Prevalence of mood and substance use disorders among patients seeking primary care office-based buprenorphine/naloxone treatment. Drug Alcohol 
Depend 127(1-3):243-247. https://doi.org/10.1016/j.drugalcdep .2012 .06 .020

7. Jones CM, McCance-Katz EF (2019) Co-occurring substance use and mental disorders among adults with opioid use disorder. Drug Alcohol Depend 197:78-82. https://doi.org/10.1016/j.drugalcdep .2018.12.030

8. Öhlin L, Fridell M, Nyhlén A (2015) Buprenorphine maintenance program with contracted work/education and low tolerance for non-prescribed drug use: a cohort study of outcome for women and men after seven years. BMC Psychiatry 15:56. https://doi. org/10.1186/s12888-015-0415-Z

9. Troberg K, Hakansson A, Dahlman D (2019) Self-rated physical health and unmet healthcare needs among swedish patients in opioid substitution treatment. J Addict 2019:7942145. https://doi. org/10.1155/2019/7942145

10. Powelson E, Lorvick J, Lutnick A, Wenger L, Klausner J, Kral AH (2014) Unmet healthcare need among women who use methamphetamine in San Francisco. Subst Use Misuse 49(3):243-252. https://doi.org/10.3109/10826084.2013.825919

11. Chitwood DD, Comerford M, McCoy HV (2002) Satisfaction with access to health care among injection drug users, other drug users, and nonusers. J Behav Health Serv Res 29(2):189-197. https://doi. org/10.1007/BF02287705

12. Jensen LF, Pedersen AF, Bech BH, Andersen B, Vedsted P (2016) Psychiatric morbidity and non-participation in breast cancer screening. Breast 25:38-44. https://doi.org/10.1016/j.breas t.2015.10.002

13. Spithoff S, Kiran T, Khuu W et al (2019) Quality of primary care among individuals receiving treatment for opioid use disorder. Can Fam Physician 65:343-351

14. Kricker A, Burns L, Goumas C, Armstrong BK (2013) Cervical screening, high-grade squamous lesions, and cervical cancer in illicit drug users. Cancer Causes Control 24(7):1449-1457. https ://doi.org/10.1007/s10552-013-0224-y

15. Tilley DM, Hristov S, Templeton DJ, Sharp NC, O'Connor CC (2012) Cervical cancer screening and abnormalities among women in a residential drug-rehabilitation program. Aust J Prim Health 18(4):266-267. https://doi.org/10.1071/PY12067

16. Carlsen K, Hoybye MT, Dalton SO, Tjonneland A (2008) Social inequality and incidence of and survival from breast cancer in a population-based study in Denmark, 1994-2003. Eur J Cancer 44(14):1996-2002. https://doi.org/10.1016/j.ejca.2008.06.027

17. American Cancer Society (2019) Breast cancer facts and figures 2019-2020. https://www.cancer.org/content/dam/cancer-org/ research/cancer-facts-and-statistics/breast-cancer-facts-and-figur es/breast-cancer-facts-and-figures-2019-2020.pdf. Accessed 7 Feb 2020

18. Brinto LA, Gaudet MM, Gierach GL (2017) Breast cancer. In: Thun M, Linet MS, Cerhan JR, Haiman CA, Schottenfeld D (eds) Cancer epidemiology and prevention, 4th edn. Oxford University Press, New York

19. Reece A (2007) Lifetime prevalence of cervical neoplasia in addicted and medical patients. Aust N Z J Obstet Gynaecol 47(5):419-423. https://doi.org/10.1111/j.1479-828X.2007.00769 . $\mathrm{x}$

20. Nolan S, Klimas J, Wood E (2016) Alcohol use in opioid agonist treatment. Addict Sci Clin Pract 11(1):17. https://doi.org/10.1186/ s13722-016-0065-6

21. Hiscock R, Bauld L, Amos A, Fidler JA, Munafò M (2012) Socioeconomic status and smoking: a review. Ann N Y Acad Sci 1248:107-123. https://doi.org/10.1111/j.1749-6632.2011.06202 . $\mathrm{X}$

22. Gaudet MM, Gapstur SM, Sun J, Diver WR, Hannan LM, Thun MJ (2013) Active smoking and breast cancer risk: original cohort data and meta-analysis. J Natl Cancer Inst 105(8):515-525. https ://doi.org/10.1093/jnci/djt023

23. Campbell BK, Le T, Gubner NR, Guydish J (2019) Health risk perceptions and reasons for use of tobacco products among clients in addictions treatment. Addict Behav 91:149-155. https://doi. org/10.1016/j.addbeh.2018.08.037

24. Bowman J, Wiggers J, Colyvas K, Wye P, Walsh RA, Bartlem K (2012) Smoking cessation among Australian methadone clients: prevalence, characteristics and a need for action. Drug Alcohol Rev 31(4):507-513. https://doi.org/10.111 1/j.1465-3362.2011.00408.x

25. Bray F, Ferlay J, Soerjomataram I, Siegel RL, Torre LA, Jemal A (2018) Global cancer statistics 2018: GLOBOCAN estimates of incidence and mortality worldwide for 36 cancers in 185 countries. CA Cancer J Clin 68(6):394-424. https://doi.org/10.3322/ caac. 21492

26. Socialstyrelsen (2018) Screening för bröstcancer Rekommendation och bedömningsunderlag [Swedish]. https://www.socialstyr elsen.se/globalassets/sharepoint-dokument/dokument-webb/natio nella-screeningprogram/screening-brostcancer-rekommendation. pdf. Accessed 20 July 2020 (updated 22 May 2019).

27. Anell A, Glenngard AH, Merkur S (2012) Sweden: health system review. Health Syst Transit 14:1-159

28. Miller-Lloyd L, Landry J, Macmadu A, Allard I, Waxman M (2020) Barriers to healthcare for people who inject drugs: a survey at a syringe exchange program. Subst Use Misuse 55(6):896-899. https://doi.org/10.1080/10826084.2019.1710207

29. Centralförbundet för alkohol-och narkotikaupplysning (2002) Narkotikamissbruk och marginalisering MAX-projektet, slutrapport [Swedish]. https://wwwcanse.cdn.triggerfish.cloud/uploa ds/2020/01/can-rapportserie-65-narkotikamissbruk-och-margi nalisering-max-projektet-slutrapport.pdf. Accessed 11 Mar 2020

30. Mitchell AJ, Pereira IE, Yadegarfar M, Pepereke S, Mugadza V, Stubbs B (2014) Breast cancer screening in women with mental illness: comparative meta-analysis of mammography uptake. Br J Psychiatry 205(6):428-435. https://doi.org/10.1192/bjp. bp. 114.147629

31. Cancerfonden (2013) Cancerfondsrapporten 2013 [Swedish]. https ://static-files.cancerfonden.se/cancerfondsrapporten-2013_15205 01722.pdf. Accessed 6 Feb 2020

32. Mattsson B, Wallgren A (1984) Completeness of the Swedish cancer register. Non-notified cancer cases recorded on death certificates in 1978. Acta Radiol Oncol 23:305-313. https://doi. org/10.3109/02841868409136026

33. Barlow L, Westergren K, Holmberg L, Talbäck M (2009) The completeness of the Swedish Cancer Register: a sample survey for year 1998. Acta Oncol 48:27-33. https://doi.org/10.1080/02841 860802247664

34. Socialstyrelsen (2012) Cancer incidence in Sweden 2011. https ://www.socialstyrelsen.se/globalassets/sharepoint-dokument/artik elkatalog/statistik/2012-12-19.pdf. Accessed 22 July 2020

35. Ahrens W, Pigeot I (2005) Use of disease registers. Handbook of epidemiology. Springer, Berlin

36. SCB (2011) SCB-data för forskning 2011 [Microdata at Statistics Sweden for research purposes 2011]. https://www.su.se/polopoly_ fs/1.55468.1321514479!/SCB_data_for_forskare.pdf. Accessed 22 July 2020

37. Ludvigsson JF, Andersson E, Ekbom A et al (2011) External review and validation of the Swedish national inpatient register. BMC Public Health 11:450. https://doi. org/10.1186/1471-2458-11-450

38. Edwards AC, Ohlsson H, Sundquist J, Sundquist K, Kendler KS (2020) Socioeconomic sequelae of drug abuse in a Swedish national cohort. Drug Alcohol Depend 212:107990. https://doi. org/10.1016/j.drugalcdep.2020.107990 
39. Kendler KS, Ohlsson H, Clouston S, Fagan AA, Sundquist J, Sundquist K (2020) The causal effect of resilience on risk for drug abuse: a Swedish national instrumental variable, co-relative and propensity-score analysis. Psychol Med 2020:1-7. https://doi. org/10.1017/S0033291719003842

40. Centralförbundet för alkohol- och narkotikaupplysning (2019) Drogutvecklingen i Sverige [Swedish]. https://wwwcanse.cdn. triggerfish.cloud/uploads/2020/01/can-rapport-180-drogutveck lingen-i-sverige-2019.pdf. Accessed 14 Feb 2020.
Publisher's Note Springer Nature remains neutral with regard to jurisdictional claims in published maps and institutional affiliations. 